Article

\title{
Research on Long-Lived Room-Temperature Phosphorescence of Carbazole-Naphthalimide Polylactides
}

\author{
Zhiwei Li ${ }^{-}$and Xingyuan Zhang *(1) \\ CAS Key Laboratory of Soft Matter Chemistry, Department of Polymer Science and Engineering, University of \\ Science and Technology of China, Hefei 230026,China; lvlvlzw@mail.ustc.edu.cn \\ * Correspondence: zxym@ustc.edu.cn
}

Received: 12 February 2020; Accepted: 22 March 2020; Published: 2 April 2020

check for updates

\begin{abstract}
Two types of naphthalimide derivatives were synthesized by introducing a carbazole group and an n-butyl, respectively, into the naphthalimide system. The electron-donating ability of two kinds of derivatives was investigated by the electrochemical method. These two types of derivatives were used as initiators for the polymerization of $\mathrm{D}$ and L-lactide polymerization. Here, the emission and UV-vis absorption serve as the main focus. Compared with solely donor-initiated polylactide (PLA), the PLA with a donor-acceptor structure has a more efficient phosphorescence emission, of which the longest phosphorescence lifetime is up to $407 \mathrm{~ms}$. The experimental results reveal the existence of charge-transfer states in the donor-acceptor-ended polymer. Due to the role of charge-transfer states, a red phosphorescent polymer was developed. Theoretically, these desirable advantages render synthesized PLAs a potential candidate for bioimaging and anti-counterfeiting.
\end{abstract}

Keywords: polymer long-lived room temperature phosphorescence (RTP); donor-acceptor; intersystem crossing; charge-transfer state; red RTP

\section{Introduction}

In recent years, purely organic materials with room temperature phosphorescence (RTP) have attracted increasing attention because of their tremendous applications in chemosensors [1,2], bioimaging [3,4], optoelectronics [5-8], data storage [9,10], and organic light-emitting diode [11]. A key to realizing efficient RTP is to promote the intersystem crossing (ISC) process. Metal and organic ligand complexes have been a popular design motif because metal to ligand or ligand to metal charge-transfer (CT) states can effectively enhance spin-orbital coupling between well-separated singlet and triplet states. However, these metal-ligand complexes are generally expensive, toxic, and moisture-instable. Therefore, the development of environmentally friendly and easily modified pure organic RTP materials is of urgent importance [12,13]. There have been plenty of reports of pure organic small molecules generating RTP through crystallization [14-18]. For phosphorescent polymer materials, ring-opening polymerization, free radical binary co-polymerization, and covalent cross-linking reactions are considered to be a reasonable chemical strategy to achieve phosphorescent polymer materials. Zhou et al. [19] incorporated a benzophenone derivative with a donor-acceptor structure into an aqueous polyurethane, and the aqueous polyurethane material will exhibit room-temperature phosphorescence. Fraser and Zhang et al. [20] designed a series of dual-emissive polymers with both fluorescence and RTP based on difluoroborn dibenzoylmethane derivatives. Other polymers for organic RTP have been reported [21,22]. These non-doped phosphorescent polymers are derived from the RTP of the polymer itself, with no additional matrix or composite material that facilitates phosphorescence generation. Although some of the above work also produced some pure organic room 
temperature phosphorescent materials, there are still some problems: The color range of polymer-based RTP is very narrow [23], and there are few reports of red phosphorescent polymer materials, so it is urgent to design and synthesize new phosphorescent units to overcome this problem [24]; compared with inorganic phosphorescent materials, the RTP lifetime of pure organic materials is relatively short (usually $<10 \mathrm{~ms}$ ) [25], so the preparation of long-lived pure organic RTP polymer materials still presents challenges.

Generally, for the naphthalimide structure, the high energy splitting between singlet and triplet states leads to a weak or even unobservable RTP [26]. Inspired by the role of CT states in inducing RTP, a carbazole subunit was introduced into the naphthalimide core to form a donor-acceptor dyad (DAD). By utilizing the CT states as the bridge for the communication between singlet and triplet excitons, the conventional fluorescent naphthalimide is converted into fluorescence and RTP dual emission. Given the conjugation structure of DAD, it is common that aggregation-caused quenching (ACQ) weakens the photoluminescence quantum yield (PLQY) or shuts down the radiative channel. To tackle this notorious issue, the designed DADs are used as initiators for ring-opening polymerization of $\mathrm{D}$, L-lactide, which has more migration-resistant, homogenous luminescence than the traditional physical mixing method.

Considering that most luminescent materials are used in the solid state, the optical characterization for the synthesized luminescent PLAs will be mainly investigated in the film state. It is found that the photoluminescence of polylactic acid with a donor-acceptor structure is dominated by phosphorescence and that the synthesized carbazole-naphthalimide PLA has a phosphorescence lifetime of up to $407 \mathrm{~ms}$. The synthesis of a red phosphorescent polymer has been achieved. These desirable advantages make synthetic PLA a potential candidate for biological imaging and security.

\section{Experimental}

\subsection{Reagents and Instruments}

The 4-Chloro-1,8-naphthalic anhydride (purity, 94\%) was purchased from Energy Chemical Co., Ltd. and used without further purification; 3-amino-9-ethylcarbazole (purity, 95\%) was purchased from Macklin Reagent Co., Ltd. and used as received; ethylene glycol (Analytical Reagent )was purchased from Shanghai Titan Science and Technology Co. Ltd.; anhydrous potassium carbonate, dimethyl sulfoxide, 2-mercaptoethanol, n-butylamine, and anhydrous ethanol were purchased from Sinopharm Chemical Reagent Co., Ltd. and used as received.

All nuclear magnetic resonance (NMR) spectra were recorded on a Bruker AV300 NMR (300 MHz for ${ }^{1} \mathrm{H}$ ) spectrometer operated in the Fourier transform mode. $\mathrm{CDCl}_{3}$ and DMSO-d6 were used as the solvent. NMR chemical shifts were reported in standard format as values in ppm relative to deuterated solvents $\left(\mathrm{CDCl}_{3}\right.$ and DMSO-d6). Molecular weights and molecular weight distributions were determined by gel permeation chromatography (GPC) equipped with Waters 1515 pump and Waters 2414 differential refractive index detector (set at $35^{\circ} \mathrm{C}$ ). It used a series of two linear Styragel columns (HR2 and HR4) at an oven temperature of $35^{\circ} \mathrm{C}$. The eluent was THF at a flow rate of $1.0 \mathrm{~mL} / \mathrm{min}$. A series of low polydispersity polystyrene standards were employed for calibration. Differential Pulse Voltammetry (DPV) experiments were carried out on a electrochemical analyzer (Bioanalysics, CV50W), scan speed: $20 \mathrm{Mv} / \mathrm{s}$. UV-vis-NIR absorption spectra were recorded on a SOLID3700 UV-vis-NIR spectrometer. Steady-state emission and delayed photoluminescence spectra were conducted on a F-4600 (Hitachi) spectrofluorometer, the slit widths were both set at $5 \mathrm{~nm}$ for excitation and emission. Fluorescence and phosphorescence lifetime data were acquired with a $1 \mathrm{MHz}$ LED laser with the excitation peak at $370 \mathrm{~nm}$. Lifetime data were analyzed with DataStation v6.6 (Horiba Scientific). 


\subsection{Synthesis}

2.2.1. Synthesis of 6-chloro-2-(9-ethyl-9H-carbazol-3-yl)-1H-benzo[de]isoquinoline-1,3(2H)-dione(A)

The 4-Chloro-1,8-naphthalic anhydride (1 g) and 3-amino-9-ethylcarbazole (1.367 g) (molar ratio of 1: 1.5) were added to a $250 \mathrm{~mL}$ single-necked flask, and $50 \mathrm{~mL}$ of ethylene glycol was used as a solvent. The reaction was carried out at a temperature of $120{ }^{\circ} \mathrm{C}$ overnight, and the reaction was monitored by TLC technology. After the reaction was completed, it was cooled to room temperature, and sufficient methanol was added. When precipitation occurred, suction filtration and drying was used to obtain product A (Scheme 1) (1.45 g), with a yield of 79.4\%. ${ }^{1} \mathrm{H}$ NMR (300 MHz, DMSO-d6) $\delta=8.69(\mathrm{~d}, \mathrm{~J}=8.5,1 \mathrm{H}), 8.64(\mathrm{~d}, \mathrm{~J}=7.2,1 \mathrm{H}), 8.48(\mathrm{~d}, \mathrm{~J}=7.9,1 \mathrm{H}), 8.17(\mathrm{~d}, \mathrm{~J}=1.9,1 \mathrm{H}), 8.09(\mathrm{dt}, \mathrm{J}=16.9$, $6.9,3 \mathrm{H}), 7.74(\mathrm{~d}, \mathrm{~J}=8.6,1 \mathrm{H}), 7.68(\mathrm{~d}, \mathrm{~J}=8.3,1 \mathrm{H}), 7.53-7.44(\mathrm{~m}, 2 \mathrm{H}), 7.22(\mathrm{t}, \mathrm{J}=7.4,1 \mathrm{H}), 4.53(\mathrm{q}, \mathrm{J}=7.0$, $2 \mathrm{H}), 1.38(\mathrm{t}, \mathrm{J}=7.1,3 \mathrm{H})$.
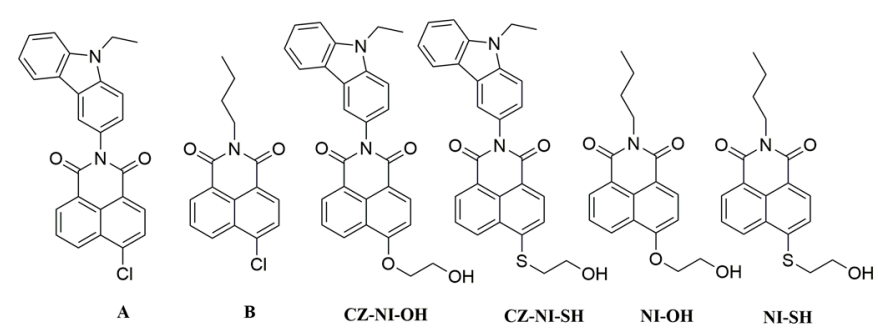

Scheme 1. Molecular structures of intermediates A, B and four naphthalimide derivatives.

\subsubsection{Synthesis of 2-butyl-6-chloro-1H-benzo[de]isoquinoline-1,3(2H)-dione(B)}

A total of $1 \mathrm{~g}$ of 4-chloro-1,8-naphthalic anhydride was put into a $250 \mathrm{~mL}$ single-necked flask, and then $50 \mathrm{~mL}$ of absolute ethanol was added. Then, $0.6278 \mathrm{~g}$ of n-butylamine was diluted in $5 \mathrm{~mL}$ of absolute ethanol and was added to the reaction system. The reaction time ended after $12 \mathrm{~h}$. After the reaction was cooled to room temperature, a large amount of deionized water was added. When a solid precipitated out, it underwent suction filtration, washing with deionized water and absolute ethanol, and drying to obtain product B (Scheme 1) $(0.545 \mathrm{~g})$ with a yield of $44 \% .{ }^{1} \mathrm{H} \mathrm{NMR}(300 \mathrm{MHz}, \mathrm{CDCl} 3)$ $\delta=8.65(\mathrm{t}, \mathrm{J}=9.1,1 \mathrm{H}), 8.59(\mathrm{~d}, \mathrm{~J}=8.5,1 \mathrm{H}), 8.53-8.46(\mathrm{~m}, 1 \mathrm{H}), 7.91-7.77(\mathrm{~m}, 2 \mathrm{H}), 4.21-4.14(\mathrm{~m}, 2 \mathrm{H})$, $1.78-1.66(\mathrm{~m}, 2 \mathrm{H}), 1.52-1.38(\mathrm{~m}, 2 \mathrm{H}), 0.98(\mathrm{t}, \mathrm{J}=7.3,3 \mathrm{H})$.

2.2.3. Synthesis of 2-(9-ethyl-9H-carbazol-3-yl)-6-(2-hydroxyethoxy)-1H-benzo[de]isoquinoline1,3(2H)-dione (CZ-NI-OH)

A total of $1 \mathrm{~g}$ of $\mathrm{A}$ and $1.3248 \mathrm{~g}$ of anhydrous potassium carbonate (molar ratio of 1:4) were added to a $250 \mathrm{~mL}$ single-necked flask, and $50 \mathrm{~mL}$ of ethylene glycol was added; this was reacted at a temperature of $120^{\circ} \mathrm{C}$ for $12 \mathrm{~h}$ and was monitored by TLC reaction. When the reaction was complete, the entire reaction system was cooled to room temperature and a large amount of deionized water was added. The mixture was stirred at room temperature with a stirrer until the solid precipitated, and this was then filtered with suction. The obtained solid was placed in a vacuum oven to obtain the substance CZ-NI-OH (Scheme 1) (0.72 g), with a yield of 66.6\%. ${ }^{1} \mathrm{H}$ NMR (300 MHz, DMSO-d6) $\delta=8.72$ $(\mathrm{dt}, \mathrm{J}=17.1,8.6,1 \mathrm{H}), 8.59-8.43(\mathrm{~m}, 2 \mathrm{H}), 8.19-8.08(\mathrm{~m}, 2 \mathrm{H}), 7.88(\mathrm{dd}, \mathrm{J}=8.3,7.4,1 \mathrm{H}), 7.76-7.63(\mathrm{~m}, 2 \mathrm{H})$, $7.55-7.32(\mathrm{~m}, 3 \mathrm{H}), 7.21(\mathrm{t}, \mathrm{J}=7.4,1 \mathrm{H}), 5.16(\mathrm{t}, \mathrm{J}=5.8,1 \mathrm{H}), 4.60-4.45(\mathrm{~m}, 2 \mathrm{H}), 4.38(\mathrm{t}, \mathrm{J}=4.6,2 \mathrm{H})$, $3.94(\mathrm{dd}, \mathrm{J}=9.7,5.3,2 \mathrm{H}), 1.38(\mathrm{t}, \mathrm{J}=7.1,3 \mathrm{H})$.

2.2.4. Synthesis of 2-(9-ethyl-9H-carbazol-3-yl)-6-((2-hydroxyethyl)thio)-1H-benzo[de]isoquinoline1,3(2H)-dione (CZ-NI-SH)

A total of $1 \mathrm{~g}$ of intermediate A, $0.28 \mathrm{~g}$ of 2-mercaptoethanol, and $1.3248 \mathrm{~g}$ of anhydrous potassium carbonate (molar ratio 1:1.5:4) were placed in a $250 \mathrm{~mL}$ single-necked flask, and $50 \mathrm{~mL}$ of dimethyl sulfoxide (DMSO) was added. The reaction temperature was $50{ }^{\circ} \mathrm{C}$ and the reaction time was $3 \mathrm{~h}$. 
After the reaction was complete, as in the previous treatment, a sufficient amount of deionized water was added, and this was stirred until a solid precipitated (if there was no solid precipitate, the extraction was performed with dichloromethane), which was then filtered with suction. The precipitated solid was dried in a vacuum oven to obtain the product CZ-NI-SH (Scheme 1) $(0.695 \mathrm{~g})$, with a yield of 62.1\%. ${ }^{1} \mathrm{H}$ NMR $(300 \mathrm{MHz}, \mathrm{DMSO}-\mathrm{d} 6) \delta=8.63(\mathrm{~d}, \mathrm{~J}=8.5,1 \mathrm{H}), 8.56(\mathrm{~d}, \mathrm{~J}=7.2,1 \mathrm{H}), 8.41(\mathrm{~d}, \mathrm{~J}=7.9,1 \mathrm{H})$, 8.18-8.09 (m, 2H), $7.93(\mathrm{t}, \mathrm{J}=7.9,1 \mathrm{H}), 7.84(\mathrm{~d}, \mathrm{~J}=8.0,1 \mathrm{H}), 7.69(\mathrm{dd}, \mathrm{J}=21.9,8.5,2 \mathrm{H}), 7.53-7.39(\mathrm{~m}, 2 \mathrm{H})$, $7.21(\mathrm{t}, \mathrm{J}=7.4,1 \mathrm{H}), 5.18(\mathrm{t}, \mathrm{J}=5.5,1 \mathrm{H}), 4.52(\mathrm{q}, \mathrm{J}=6.9,2 \mathrm{H}), 3.78(\mathrm{q}, \mathrm{J}=6.1,2 \mathrm{H}), 3.39(\mathrm{dd}, \mathrm{J}=12.8,6.4$, $2 \mathrm{H}), 1.38(\mathrm{t}, \mathrm{J}=7.0,3 \mathrm{H})$.

\subsubsection{Synthesis of 2-butyl-6-(2-hydroxyethoxy)-1H-benzo[de]isoquinoline-1,3(2H)-dione(NI-OH)}

A total of $1 \mathrm{~g}$ of intermediate B, $1.932 \mathrm{~g}$ of anhydrous potassium carbonate (molar ratio 1:4) and $50 \mathrm{~mL}$ of ethylene glycol were added to a $250 \mathrm{~mL}$ single-necked flask; this was reacted at a temperature of $130^{\circ} \mathrm{C}$ for $12 \mathrm{~h}$ and the reaction was monitored by TLC. Finally, the system was cooled to room temperature, and then a large amount of deionized water was added and stirred until a solid precipitated out. After suction filtration was complete, the product was dried under a vacuum to obtain the product NI-OH (Scheme 1) $\left(0.487 \mathrm{~g}\right.$ ), with a yield of $44.4 \% .{ }^{1} \mathrm{H}$ NMR (300 MHz, DMSO-d6) $\delta=8.63$ $(\mathrm{d}, \mathrm{J}=8.4,1 \mathrm{H}), 8.45(\mathrm{dd}, \mathrm{J}=25.4,7.8,2 \mathrm{H}), 7.81(\mathrm{t}, \mathrm{J}=7.8,1 \mathrm{H}), 7.29(\mathrm{~d}, \mathrm{~J}=8.3,1 \mathrm{H}), 5.11(\mathrm{t}, \mathrm{J}=5.7,1 \mathrm{H})$, $4.33(\mathrm{t}, \mathrm{J}=4.6,2 \mathrm{H}), 4.08-3.96(\mathrm{~m}, 2 \mathrm{H}), 3.91(\mathrm{dd}, \mathrm{J}=9.8,5.0,2 \mathrm{H}), 1.68-1.54(\mathrm{~m}, 2 \mathrm{H}), 1.43-1.30(\mathrm{~m}, 2 \mathrm{H})$, $0.93(\mathrm{t}, \mathrm{J}=7.3,3 \mathrm{H})$.

\subsubsection{Synthesis of 2-butyl-6-((2-hydroxyethyl)thio)-1H-benzo[de]isoquinoline-1,3(2H)-dione(NI-SH)}

A total of $1 \mathrm{~g}$ of Intermediate B, $0.4095 \mathrm{~g}$ of 2-mercaptoethanol, $1.932 \mathrm{~g}$ of anhydrous potassium carbonate (molar ratio of 1:1.5:4), and $50 \mathrm{~mL}$ of dimethyl sulfoxide as solvent were reacted at a temperature of $50{ }^{\circ} \mathrm{C}$; the reaction time was $3 \mathrm{~h}$, the same as for the previous step. After the reaction was complete, the reaction was withdrawn, and it was cooled to room temperature. We added a large amount of deionized water and then stirred until a solid precipitate appeared in the system, and the precipitated solid was obtained by suction filtration. The product NI-SH (Scheme 1) was obtained by drying $(0.523 \mathrm{~g})$, with a yield of $45.4 \% .{ }^{1} \mathrm{H}$ NMR $(300 \mathrm{MHz}$, DMSO-d6) $\delta=8.58-8.50(\mathrm{~m}, 2 \mathrm{H})$, $8.36(\mathrm{~d}, \mathrm{~J}=7.9,1 \mathrm{H}), 7.88(\mathrm{dd}, \mathrm{J}=8.4,7.4,1 \mathrm{H}), 7.79(\mathrm{~d}, \mathrm{~J}=8.0,1 \mathrm{H}), 5.16(\mathrm{t}, \mathrm{J}=5.5,1 \mathrm{H}), 4.07-3.99(\mathrm{~m}, 2 \mathrm{H})$, $3.75(\mathrm{q}, \mathrm{J}=6.2,2 \mathrm{H}), 3.37(\mathrm{~d}, \mathrm{~J}=6.5,2 \mathrm{H}), 1.67-1.55(\mathrm{~m}, 2 \mathrm{H}), 1.34(\mathrm{~m}, 2 \mathrm{H}), 0.93(\mathrm{t}, \mathrm{J}=7.4,3 \mathrm{H})$.

\subsubsection{Synthesis of PLAs}

To obtain CZ-NI-OH: D, L-lactide, stannous octoate was used at a molar ratio of 1:150:0.1. We took $0.5 \mathrm{~g}$ of $\mathrm{D}$, L-Lactide, put it into a $10 \mathrm{~mL}$ Knotes bottle, passed it through nitrogen, made the whole reaction system oxygen-free, then added stannous octoate diluted with n-hexane and immersed the whole ball of the flask. A viscous solid formed in an oil bath at $135^{\circ} \mathrm{C}$. After the mixture was cooled to room temperature, the crude polymer was purified by precipitation from $\mathrm{CH}_{2} \mathrm{Cl}_{2} / \mathrm{ice}_{\mathrm{CH}} \mathrm{OH}(\times 3)$ at this temperature. The resulting solid was further precipitated from $\mathrm{CH}_{2} \mathrm{Cl}_{2} /$ hexane $(\times 3)$ to give a final polymer [27], CZ-NI-O-PLA (Scheme 2). Following the same operation, three other polylactides were sequentially synthesized: CZ-NI-S-PLA, NI-O-PLA, and NI-S-PLA (Scheme 2).

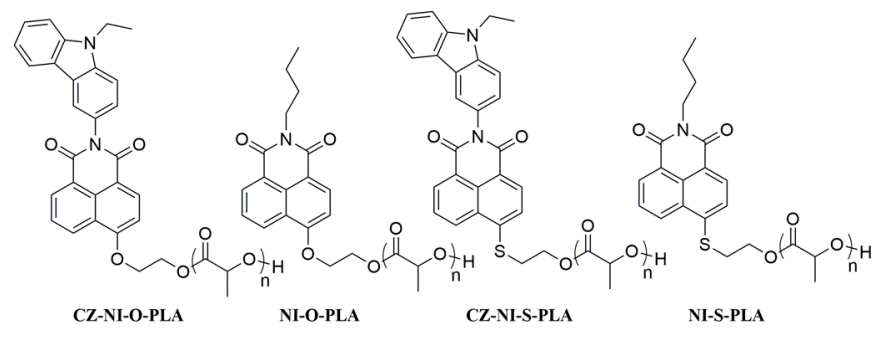

Scheme 2. Polylactides initiated by carbazole-naphthalimide dyads and naphthalimide-functionalized polylactides. 


\section{Result and Discussion}

\subsection{Characterization of Electrochemical Properties of Four Derivatives}

According to the synthesis steps mentioned, we synthesized four kinds of monohydroxy monomers (Scheme 1), and the ${ }^{1} \mathrm{H}$ NMR results verified the correctness of their structures.

We research the electrochemical properties of small molecules and use Differential Pulse Voltammetry (DPV) to test these four small molecules. The curve of DPV is more refined than the conventional Cyclic Voltammetry $(\mathrm{CV})$.

The DPV curves of these four molecules (Figure 1) have peaks at positive potentials. The oxidation potentials of the molecules NI-OH and NI-SH are around $1.6 \mathrm{eV}$, while the oxidation potentials of CZ-NI-OH and CZ-NI-SH are about $1.2 \mathrm{eV}$. Combining these four molecular structures, the electron-deficient sites of the molecules are all naphthalimide structures, so the reduction potentials of all molecules are around -1.6 eV. Compared with molecules CZ-NI-OH and NI-OH, the oxidation potential of CZ-NI-OH is lower and the donor ability is stronger. Through electrochemical experiments, the experimental results are consistent with our previous conjectures. When a molecule has a donor-acceptor structure, the lower the oxidation potential, the stronger the electron donor capacity, and the easier the charge separation is to produce an intramolecular charge transfer state.
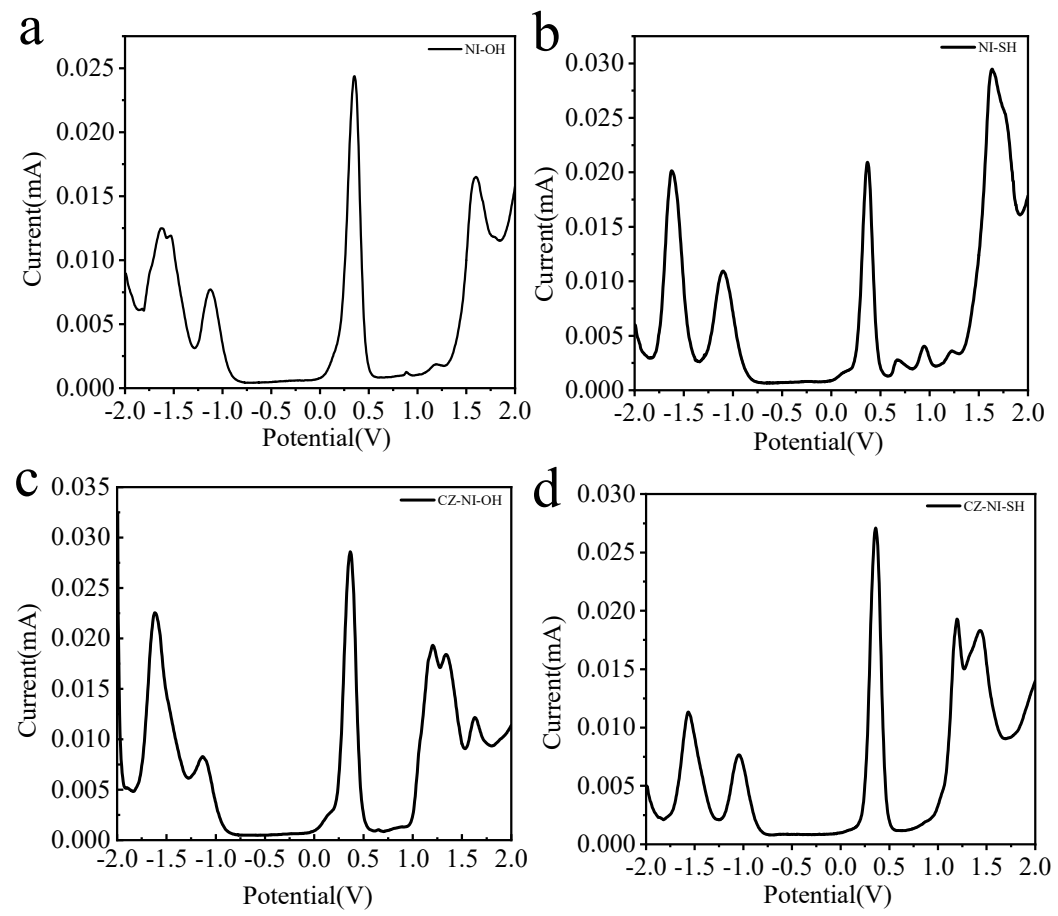

Figure 1. DPV curves of small molecules NI-OH (a), NI-SH (b), CZ-NI-OH (c) and CZ-NI-SH (d).

\subsection{Photoluminescence Properties of Polylactides}

Under a nitrogen atmosphere, these four functional monomers were subjected to ring-opening polymerization (ROP) with D, L-lactide at $130{ }^{\circ} \mathrm{C}$ to obtain polylactides. The Mn of PLA was obtained from the GPC spectrum (Table 1). The data show that the PDI of CZ-NI-O-PLA and CZ-NI-S-PLA is slightly larger than the other two types of polylactic acid. These results are attributed to the tendency of naphthalimide to form ground state dimers, which may hinder the ROP process and cause a wider distribution of $M_{\mathrm{w}}$ [27]. 
Table 1. Polylactide molecular weight and molecular weight distribution.

\begin{tabular}{ccc}
\hline Entry & $\boldsymbol{M}_{\mathbf{n}}$ & $\boldsymbol{M}_{\mathbf{w}} / \boldsymbol{M}_{\mathbf{n}}$ \\
\hline CZ-NI-O-PLA & 14,800 & 1.62 \\
CZ-NI-S-PLA & 13,100 & 1.56 \\
NI-O-PLA & 10,100 & 1.54 \\
NI-S-PLA & 13,600 & 1.47 \\
\hline
\end{tabular}

Considering that phosphorescence will be quenched by oxygen or under solution conditions, the four kinds of polylactides mentioned above were dissolved in $\mathrm{CH}_{2} \mathrm{Cl}_{2}$; then the solution mixture was dried in a glass tube to form a transparent uniform film (ca. $0.2 \mathrm{~mm}$ ).

NI-O-PLA emits dazzling blue fluorescence under the illumination of a handheld $365 \mathrm{~nm}$ UV lamp. Regardless of the steady-state emission spectrum under air or vacuum conditions (Figure 2a), the fluorescence emission spectrum of the polylactide shows almost no change. The fluorescence lifetime of the NI-O-PLA emission wavelength at $420 \mathrm{~nm}$ is $7.14 \mathrm{~ns}$ (Figure 3a, air, $298 \mathrm{~K}$ ). The two characteristics of the steady-state emission spectrum and luminescence lifetime data show that the photoluminescence of NI-O-PLA is mainly fluorescence emission. To attempt to enhance the phosphorescence emission of this system, a strong electron-donating group carbazole was introduced into the naphthalimide system to obtain a donor-acceptor covalently-linked polylactide (CZ-NI-O-PLA). Figure $2 b$ is its steady-state emission spectrum. Obviously, the steady-state emission spectrum shows completely different states under air and vacuum conditions. The emission of this polylactide film in the air is mainly fluorescent, the maximum emission wavelength is $442 \mathrm{~nm}$, and the lifetime at this emission wavelength is $5.381 \mathrm{~ns}$ (Figure 3b, air, $298 \mathrm{~K}$ ). When the glass tube was sealed in a vacuum, the maximum emission wavelength shifts from 442 to $550 \mathrm{~nm}$, and the luminescence lifetime at this wavelength is $407 \mathrm{~ms}$ (Figure 3c, vacuum, $298 \mathrm{~K}$ ). The vacuum film of CZ-NI-O-PLA emits a bright yellow phosphorescence under the irradiation of a handheld $365 \mathrm{~nm}$ UV lamp. After removing the excitation light source, the film will have a visible delay, which also explains why this polylactide film has a longer phosphorescent lifetime. The difference between the photoluminescence spectrum of CZ-NI-O-PLA under air and vacuum conditions and the luminous lifetime are all characteristics of phosphorescence emission. In its RTP spectrum (Figure 2b, blue curve), the fluorescence emission peak disappears, and only 550 and $595 \mathrm{~nm}$ phosphorescence peaks show up, which further proves that the emission of CZ-NI-O-PLA at 550 and $595 \mathrm{~nm}$ is phosphorescence emission. The RTP spectrum shows the vibration of the aromatic ring [26], that is, the emission peaks of 550 and $595 \mathrm{~nm}$ are separated by about $1500 \mathrm{~cm}^{-1}$. In the conventional concept, phosphorescence is quenched under air conditions. Generally, there is no phosphorescent peak in the steady-state spectrum under air conditions, but here we see that at the same location, there is still a phosphorescent emission peak in the steady-state emission spectrum in the air. The reason for this phenomenon is that during the preparation of the polylactide film, the formed film is dense enough. At the same time, the emission of phosphorescence is also strong, and the oxygen content in the film is not sufficient to quench the phosphorescence. When the excitation source is continuously irradiated, a similar phenomenon occurs in the film. We irradiated the CZ-NI-O-PLA film in air by a $365 \mathrm{~nm}$ hand-held UV lamp, with the strong yellow luminescence under continuous irradiation. 




NI-O-PLA

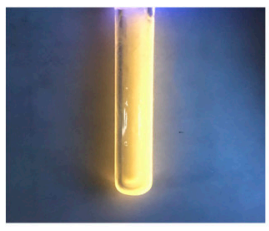

CZ-NI-O-PLA



NI-S-PLA

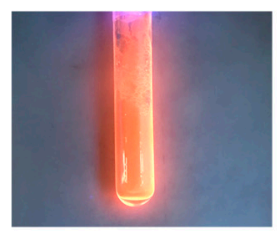

CZ-NI-S-PLA a
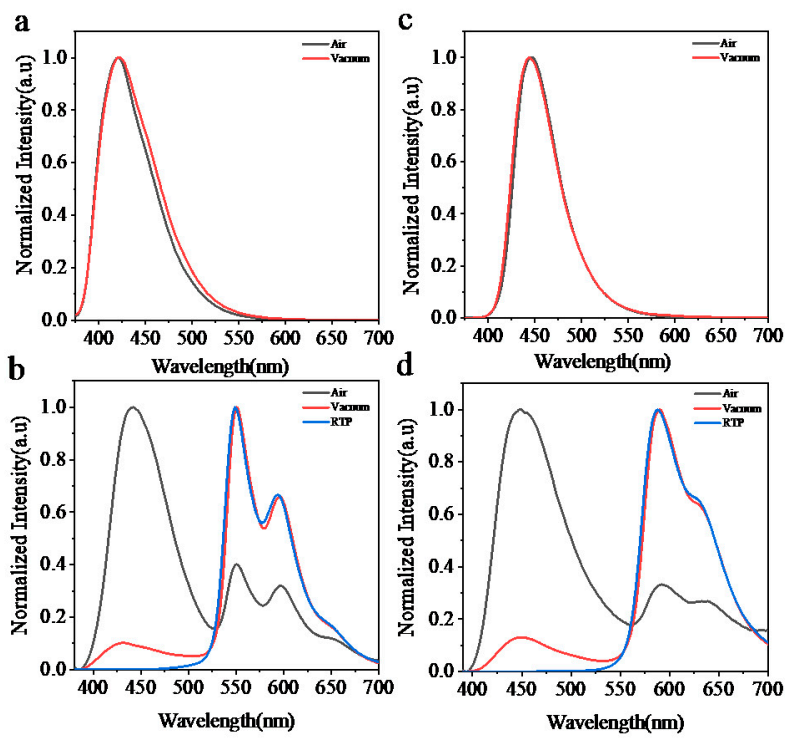

Figure 2. Left: photoluminescence photos of four polylactides films; Right: steady-state emission spectra of NI-O-PLA (a) and NI-S-PLA (c); CZ-NI-O-PLA (b) and CZ-NI-S-PLA (d) steady-state emissions and RTP spectra.


Figure 3. Time-resolved PL decay curves; NI-O-PLA 420 nm (a, air, 298 k); CZ-NI-O-PLA 442 nm (b, air, 298 k), 550 and 595 nm (c, vacuum, 298 k); NI-S-PLA 445nm (d, air, 298 k); CZ-NI -S-PLA 450 nm (e, air, 298 k), 590 and $635 \mathrm{~nm}$ (f, vacuum, 298 k); Excitation wavelength: $365 \mathrm{~nm}$.

Since the CZ-NI-O-PLA phosphorescent color is yellow, it is easy to achieve red phosphorescence. Considering the close nature of the $\mathrm{O}$ atom and the $\mathrm{S}$ atom, we replaced the $\mathrm{O}$ atom of the above molecule with the $S$ atom to obtain NI-S-PLA and CZ-NI-S-PLA. The photoluminescence of the NI-S-PLA film (Figure 2c) is basically the same as that of NI-O-PLA. The maximum emission wavelength under air and vacuum is $445 \mathrm{~nm}$. The luminescence lifetime at this wavelength is $5.91 \mathrm{~ns}$ (Figure 3d, air, 298 K). Substance CZ-NI-S-PLA emits bright red phosphorescence under the excitation light source of $365 \mathrm{~nm}$. The lifetime decay spectrum (Figure 3e,f) shows that the emission of this substance at $450 \mathrm{~nm}$ under air conditions is fluorescent emission, while the emission peaks at 590 and $635 \mathrm{~nm}$ in vacuum are phosphorescent peaks (Figure 2d). Comparing Figure $2 b, d$, the shapes of the curves are similar. 
However, the maximum emission wavelength of CZ-NI-S-PLA is slightly longer. Comparing the structures of CZ-NI-O-PLA and CZ-NI-S-PLA, the difference between these two polylactides structures is the $\mathrm{O}$ atom and the $\mathrm{S}$ atom. As the lone pair of electrons of the $\mathrm{S}$ atom forms a $\mathrm{p}-\pi$ conjugate with naphthalimide and the electrons of the entire system are delocalized to a greater extent, it is more likely to obtain red phosphorescence with lower energy, and the maximum emission wavelength of CZ-NI-S-PLA is longer. This provides a way to realize the red phosphorescent unit. Compared with the previously reported red phosphorescent unit, this unit has better solubility, is simpler and synthesis is more efficient. As red phosphorescence has a stronger penetrating ability and PLA has good biocompatibility, it has good application prospects in the field of cell imaging. Comparing the photoluminescence of these four covalently linked polylactides, we can conclude that the presence or absence of the donor-acceptor structure will have an important effect on the phosphorescence emission. Among them, NI-O-PLA and NI-S-PLA are mainly fluorescence emission, while CZ-NI-O-PLA and CZ-NI-S-PLA are mainly phosphorescence emission. Considering the difference in structure, NI-O-PLA is an electron-deficient system. However, due to the effect of carbazole, CZ-NI-O-PLA is prone to generate intramolecular charge transfer states to bridge the splitting energy between larger singlet state and triplet state $\left(\Delta E_{\mathrm{ST}}\right)$, thus promoting the intersystem crossing process. Therefore, in the photoluminescence process of CZ-NI-O-PLA, phosphorescent emission is in a dominant position to compete with fluorescence emission, resulting in the photoluminescence of the polylactide film being dominated by phosphorescence emission.

The photoluminescence properties of PLA films have been discussed. As PLA is soluble in most organic solvents, these polymeric conjugates also exhibit excellent solubility in polar solvents such as tetrahydrofuran (THF) and dichloromethane (DCM). We choose four different solvents (DCM, EA, THF, DMF). The corresponding steady-state emission spectra for the two phosphorescent polymers (CZ-NI-O-PLA, CZ-NI-S-PLA) were recorded in different solvents, which influence the luminescence properties. As can be seen, the emission maximum varies from 432 to $438 \mathrm{~nm}$ for CZ-NI-O-PLA (Figure 4a) and 432 to $439 \mathrm{~nm}$ for CZ-NI-S-PLA (Figure $4 \mathrm{~b}$ ). The solvatochromic fluorescence is typically a sign of charge transfer state [27], which is expected for the donor-acceptor type of molecules. Although the maximum emission peaks of these two phosphorescent PLA have shifted, the phenomenon of this shift is not obvious. The possible reason is that under such conditions, the CT state is a dark state, and the test under solution conditions will not have a significant shift. Therefore, we should provide more evidence to prove the CT state.
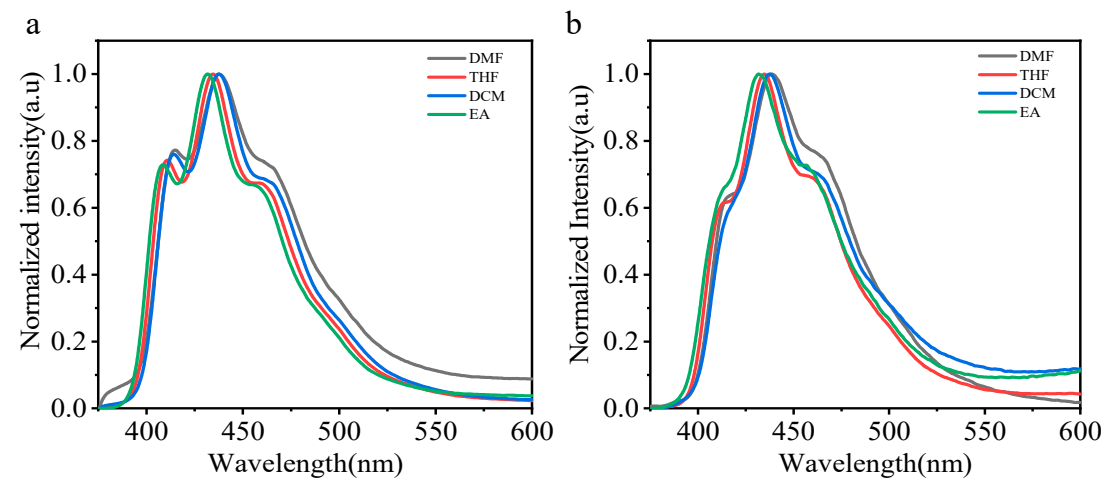

Figure 4. Fluorescence emission spectra of CZ-NI-O-PLA (a) and CZ-NI-S-PLA (b) in different polar solvents.

\subsection{UV Absorption Properties of Polylactic Acid and Verification of Intramolecular Charge Transfer State}

Four kinds of polylactic acid are dissolved in dichloromethane to control the concentration of chromophore to $10^{-5} \mathrm{~mol} / \mathrm{L}$. Observing the ultraviolet spectrum (Figure $5 \mathrm{a}$ ), compared with NI-O-PLA, the UV spectrum of CZ-NI-O-PLA has a small absorption peak at $290 \mathrm{~nm}$, which is attributed to the contribution of the carbazole structure. Methods for proving charge transfer state have been proposed 
in a large number of previous studies [28,29]. Among them, the most common and simple method is to identify it by the emission and absorption of different polar solvents [30]. We also tried to use this method to research CZ-NI-O-PLA and CZ-NI-S-PLA. Polylactide was dissolved in solvents of different polarities (order of polarity of the solvent: $\mathrm{DCM}<\mathrm{THF}<\mathrm{EA}<\mathrm{DMF}$ ), and the concentration of chromophore was controlled at $10^{-5} \mathrm{~mol} / \mathrm{L}$. Figure $5 \mathrm{~b}, \mathrm{c}$ shows the UV-vis spectra of CZ-NI-O-PLA and CZ-NI-S-PLA under different polar solvents. It was found that the absorption peak of CZ-NI-O-PLA will redshift as the polarity of the solvent increases (emission wavelength: $\lambda_{\mathrm{DMF}}>\lambda_{\mathrm{EA}}>\lambda_{\mathrm{THF}}>\lambda_{\mathrm{DCM}}$ ).
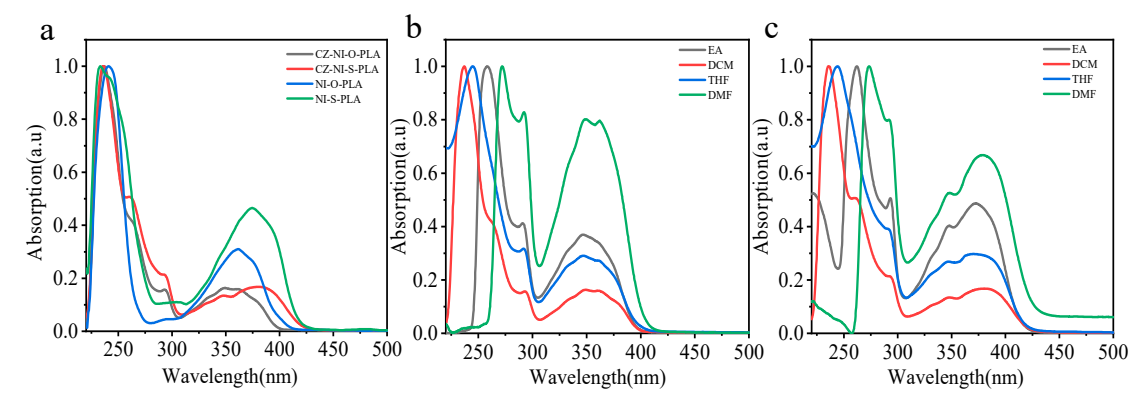

Figure 5. (a) UV-vis spectra of CZ-NI-O-PLA, CZ-NI-S-PLA, NI-O-PLA and NI-S-PLA, (solvent DCM); and UV-vis spectra in different polar solvents for CZ-NI-O-PLA (b) and CZ-NI-S-PLA (c).

In the transition band of $\pi-\pi^{*}$ in the ultraviolet spectrum, the absorption peak is red-shifted from 235 to $270 \mathrm{~nm}$. CZ-NI-S-PLA will show a similar phenomenon in the same operation. This phenomenon proves that CZ-NI-O-PLA and CZ-NI-S-PLA have the characteristics of intramolecular charge transfer state, and the areas and characteristics of redshift are significant features for $\pi-\pi^{*}$ transitions.

Taking the UV absorption in different polar solvents into account, the experimental results appear to confirm our conjecture. Then, the emission of these two polylactides in different polar solvents should also have this phenomenon, but the shift of the emission peak (Figure $4 a, b$ ) is not as obvious as we thought. The possible reason is that under such conditions, the CT state is a dark state, and the test under solution conditions will not have a significant shift. Considering the existence of this problem, we changed our thinking to verify the emission of CZ-NI-O-PLA and CZ-NI-S-PLA in different polar solvents.

Chromophores are dispersed in different polymer matrices. Polymethyl methacrylate (PMMA), polystyrene (PS), poly N, N-methyl dimethacrylate (PDMA), and polyurethane (PU) were selected as different polar dispersive matrices. We dispersed the small molecules $\mathrm{CZ}-\mathrm{NI}-\mathrm{OH}$ and $\mathrm{CZ}-\mathrm{NI}-\mathrm{SH}$ in the above four polymer matrices, with a mass fraction of $1 \%$. Then, $10 \mathrm{~mL}$ of solvent $\mathrm{DCM}$ was used to dissolve it, and this was then blown into a glass tube to form a transparent and uniform film. It is believed that the chromophore is dissolved in a polymer matrix of different polarities. The fluorescence emission spectrum of small molecules dispersed in four polymer matrices (Figure 6a,b) is the main evidence to prove the CT state. The steady-state emission peaks of the blend in air increased sequentially from PMMA to PU, and the positions of the emission peaks shifted to red as the polarity of the polymer matrix increased $\left(\lambda_{\mathrm{PU}}>\lambda_{\mathrm{PS}}>\lambda_{\mathrm{PDMA}}>\lambda_{\mathrm{PMMA}}\right)$. In this operation, considering that when small molecules are blended into the polymer, the entire system is not stable, and small molecules will have different interactions (such as $\pi-\pi$, H-bonds, etc ... ) with the polymer matrix. For this reason, we use the fastest pace possible when testing. Although we have performed this process as quickly as possible, in fact, we could not control the interaction between the matrix and the dye; therefore, we chose different polymers as dispersed matrices in order to qualitatively compare the influence of the matrices. In combination with the absorption and emission spectra in different polar solvents, the emission in different polymer matrices can be used as an auxiliary to prove the existence of charge transfer states. 

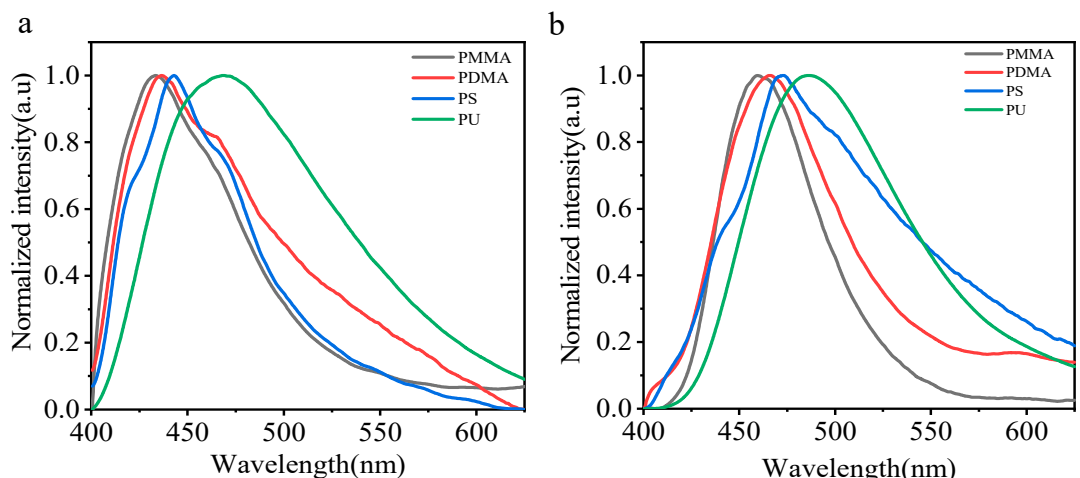

Figure 6. Steady-state emission spectra of CZ-NI-OH (a) and CZ-NI-SH (b) dispersed in different polymer matrices.

Based on the above test results of various forms of ultraviolet absorption and fluorescence emission, we firmly believe that the small molecules CZ-NI-OH and CZ-NI-SH exist in the intramolecular charge transfer state.

\section{Conclusions}

In this work, the synthesized polylactide with carbazole-naphthalimide structure has the characteristics of long-lived room temperature phosphorescence emission, and its lifetime can be up to $407 \mathrm{~ms}$; by introducing different groups to the naphthalimide system, the fluorescence/phosphorescence emission ratio of this type of polylactide can be tuned. Among the two types of polylactic acid mainly dominated by phosphorescent emission, $\mathrm{O}$ and $\mathrm{S}$ atoms will also have an important effect on the system. Polylactide containing $\mathrm{O}$ atoms has a longer phosphorescence lifetime, while the maximum emission wavelength of polylactide containing $S$ atoms is relatively longer, and it is more likely to produce red room-temperature phosphorescence.

Author Contributions: Conceptualization, Z.L.; Data curation, Z.L.; Formal analysis, Z.L.; Investigation, Z.L.; Writing-Original draft, Z.L.; Writing-Review \& editing, X.Z. All authors have read and agreed to the published version of the manuscript.

Funding: This research was funded by the National High Technology Research and Development Program of China, grant number 2015AA033903.

Conflicts of Interest: The authors declare no conflict of interest.

\section{References}

1. Yanai, N.; Kitayama, K.; Hijikata, Y.; Sato, H.; Matsuda, R.; Kubota, Y.; Takata, M.; Mizuno, M.; Uemura, T.; Kitagawa, S. Gas detection by structural variations of fluorescent guest molecules in a flexible porous coordination polymer. Nat. Mater. 2011, 10, 787-793. [CrossRef] [PubMed]

2. Steinegger, A.; Klimant, I.; Borisov, S.M. Purely organic dyes with thermally activated delayed fluorescence-A versatile class of indicators for optical temperature sensing. Adv. Opt. Mater. 2017, 5, 1700372. [CrossRef]

3. Miao, Q.; Pu, K. Organic Semiconducting Agents for Deep-Tissue Molecular Imaging: Second Near-Infrared Fluorescence, Self-Luminescence, and Photoacoustics. Adv. Mater. 2018, 30, 1801778. [CrossRef] [PubMed]

4. Uoyama, H.; Goushi, K.; Shizu, K.; Nomura, H.; Adachi, C. Highly efficient organic light-emitting diodes from delayed fluorescence. Nature 2012, 492, 234-238. [CrossRef]

5. Liu, Y.; Li, C.; Ren, Z.; Yan, S.; Bryce, M.R. All-organic thermally activated delayed fluorescence materials for organic light-emitting diodes. Nat. Rev. Mater. 2018, 3, 18020. [CrossRef]

6. Cai, X.; Chen, D.; Gao, K.; Gan, L.; Yin, Q.; Qiao, Z.; Chen, Z.; Jiang, X.; Su, S.J. “Trade-Off” Hidden in Condensed State Solvation: Multiradiative Channels Design for Highly Efficient Solution-Processed Purely Organic Electroluminescence at High Brightness. Adv. Funct. Mater. 2018, 28, 1704927. [CrossRef] 
7. Shimada, M.; Yamanoi, Y.; Ohto, T.; Pham, S.T.; Yamada, R.; Tada, H.; Omoto, K.; Tashiro, S.; Shionoya, M.; Hattori, M.; et al. Multifunctional octamethyltetrasila[2.2]cyclophanes: Conformational variations, circularly polarized luminescence, and organic electroluminescence. J. Am. Chem. Soc. 2017, 139, 11214-11221. [CrossRef]

8. Yang, Z.; Mao, Z.; Xie, Z.; Zhang, Y.; Liu, S.; Zhao, J.; Xu, J.; Chi, Z.; Aldred, M.P. Recent advances in organic thermally activated delayed fluorescence materials. Chem. Soc. Rev. 2017, 46, 915-1016. [CrossRef]

9. Xiong, Y.; Zhao, Z.; Zhao, W.; Ma, H.; Peng, Q.; He, Z.; Zhang, X.; Chen, Y.; He, X.; Lam, J.W.Y. Designing Efficient and Ultralong Pure Organic Room-Temperature Phosphorescent Materials by Structural Isomerism. Angew. Chem. Int. Ed. 2018, 57, 7997-8001. [CrossRef]

10. Ma, X.; Xu, C.; Wang, J.; Tian, H. Amorphous Pure Organic Polymers for Heavy-Atom-Free Efficient Room-Temperature Phosphorescence Emission. Angew. Chem. Int. Ed. 2018, 57, 10854-10858. [CrossRef]

11. Wang, T.; Su, X.; Zhang, X.; Nie, X.; Huang, L.; Zhang, X.; Sun, X.; Luo, Y.; Zhang, G. Aggregation-Induced Dual-Phosphorescence from Organic Molecules for Nondoped Light-Emitting Diodes. Adv. Mater. 2019, 31, 1904273. [CrossRef] [PubMed]

12. Mukherjee, S.; Thilagar, P. Recent advances in purely organic phosphorescent materials. Chem. Commun. 2015, 51, 10988-11003. [CrossRef] [PubMed]

13. Yoshii, R.; Hirose, A.; Tanaka, K.; Chujo, Y. Functionalization of boron diiminates with unique optical properties: Multicolor tuning of crystallization-induced emission and introduction into the main chain of conjugated polymers. J. Am. Chem. Soc. 2014, 136, 18131-18139. [CrossRef] [PubMed]

14. Yuan, W.Z.; Shen, X.Y.; Zhao, H.; Lam, J.W.Y.; Tang, L.; Lu, P.; Wang, C.; Liu, Y.; Wang, Z.; Zheng, Q. Crystallization-induced phosphorescence of pure organic luminogens at room temperature. J. Phys. Chem. C 2010, 114, 6090-6099. [CrossRef]

15. Gong, Y.Y.; Tan, Y.Q.; Mei, J.; Zhang, Y.R.; Yuan, W.Z.; Zhang, Y.M.; Sun, J.Z.; Tang, B.Z. Room temperature phosphorescence from natural products: Crystallization matters. Sci. China Chem. 2013, 56, 1178-1182. [CrossRef]

16. Gong, Y.; Zhao, L.; Peng, Q.; Fan, D.; Yuan, W.Z.; Zhang, Y.; Tang, B.Z. Crystallization-induced dual emission from metal-and heavy atom-free aromatic acids and esters. Chem. Sci. 2015, 6, 4438-4444. [CrossRef]

17. Li, J.; Jiang, Y.; Cheng, J.; Zhang, Y.; Su, H.; Lam, J.W.Y.; Sung, H.H.Y.; Wong, K.S.; Kwok, H.S.; Tang, B.Z. Tuning the singlet-triplet energy gap of AIE luminogens: Crystallization-induced room temperature phosphorescence and delay fluorescence, tunable temperature response, highly efficient non-doped organic light-emitting diodes. Phys. Chem. Chem. Phys. 2015, 17, 1134-1141. [CrossRef]

18. An, Z.; Zheng, C.; Tao, Y.; Chen, R.; Shi, H.; Chen, T.; Wang, Z.; Li, H.; Deng, R.; Liu, X. Stabilizing triplet excited states for ultralong organic phosphorescence. Nat. Mater. 2015, 14, 685. [CrossRef]

19. Zhou, C.; Xie, T.; Zhou, R.; Trindle, C.O.; Tikman, Y.; Zhang, X.; Zhang, G. Waterborne polyurethanes with tunable fluorescence and room-temperature phosphorescence. ACS Appl. Mater. Interfaces 2015, 7, 17209-17216. [CrossRef]

20. Zhang, G.; Chen, J.; Payne, S.J.; Kooi, S.E.; Demas, J.N.; Fraser, C.L. Multi-emissive difluoroboron dibenzoylmethane polylactide exhibiting intense fluorescence and oxygen-sensitive room-temperature phosphorescence. J. Am. Chem. Soc. 2007, 129, 8942-8943. [CrossRef]

21. Chen, H.; Yao, X.; Ma, X.; Tian, H. Amorphous, Efficient, Room-Temperature Phosphorescent Metal-Free Polymers and Their Applications as Encryption Ink. Adv. Opt. Mater. 2016, 4, 1397-1401. [CrossRef]

22. Zhou, Q.; Cao, B.; Zhu, C.; Xu, S.; Gong, Y.; Yuan, W.Z.; Zhang, Y. Clustering-triggered emission of nonconjugated polyacrylonitrile. Small 2016, 12, 6586-6592. [CrossRef] [PubMed]

23. Gan, N.; Shi, H.; An, Z.; Huang, W. Recent Advances in Polymer-Based Metal-Free Room-Temperature Phosphorescent Materials. Adv. Funct. Mater. 2018, 28, 1802657. [CrossRef]

24. Fateminia, S.M.A.; Mao, Z.; Xu, S.; Yang, Z.; Chi, Z.; Liu, B. Organic nanocrystals with bright red persistent room-temperature phosphorescence for biological applications. Angew. Chem. Int. Ed. 2017, 56, 12160-12164. [CrossRef] [PubMed]

25. Köhler, A.; Bässler, H. Triplet states in organic semiconductors. Mater. Sci. Eng. R Rep. 2009, 66, 71-109. [CrossRef]

26. Chen, X.; Xu, C.; Wang, T.; Zhou, C.; Du, J.; Wang, Z.; Xu, H.; Xie, T.; Bi, G.; Jiang, J. Versatile room-temperature-phosphorescent materials prepared from n-substituted naphthalimides: Emission enhancement and chemical conjugation. Angew. Chem. Int. Ed. 2016, 55, 9872-9876. [CrossRef] 
27. Wang, T.; Su, X.; Zhang, X.; Huang, W.; Huang, L.; Zhang, X.; Sun, X.; Luo, Y.; Zhang, G. A combinatory approach towards the design of organic polymer luminescent materials. J. Mater. Chem. C 2019, 7, 9917-9925. [CrossRef]

28. Grabowski, Z.R.; Rotkiewicz, K.; Rettig, W. Structural changes accompanying intramolecular electron transfer: Focus on twisted intramolecular charge-transfer states and structures. Chem. Rev. 2003, 103, 3899-4032. [CrossRef]

29. Iwata, S.; Tanaka, J.; Nagakura, S. Phosphorescence of the Charge-Transfer Triplet States of Some Molecular Complexes. J. Chem. Phys. 1967, 47, 2203-2209. [CrossRef]

30. Dias, F.B.; Pollock, S.; Hedley, G.; Pålsson, L.; Monkman, A.; Perepichka, I.I.; Perepichka, I.F.; Tavasli, M.; Bryce, M.R. Intramolecular charge transfer assisted by conformational changes in the excited state of fluorene-dibenzothiophene-S, S-dioxide co-oligomers. J. Phys. Chem. B 2006, 110, 19329-19339. [CrossRef]

C 2020 by the authors. Licensee MDPI, Basel, Switzerland. This article is an open access article distributed under the terms and conditions of the Creative Commons Attribution (CC BY) license (http://creativecommons.org/licenses/by/4.0/). 